\title{
PSICOPEDAGOGIA: ESTRATÉGIAS PARA TRABALHAR COM CRIANÇAS COM TRANSTORNO DE DÉFICIT DE ATENÇÃO E HIPERATIVIDADE (TDAH)
}

Drielly Adrean Batista, Rita Melissa Lepre, Rodrigo Cesar Costa , Aline kadooka

Programa de pós-graduação em psicologia da Universidade Estadual Paulista "Júlio de Mesquita Filho" - UNESP -

Assis. E-mail: driellyadrean@yahoo.com.br

\section{RESUMO}

O objetivo desse trabalho é analisar os métodos psicopedagogicos para trabalhar com crianças que apresentam Transtorno de Déficit de Atenção e Hiperatividade, seja ele no ambiente escolar ou na clinica contribuindo para o desenvolvimento cognitivo, afetivo, moral e físico dessas crianças. A metodologia utilizada é por meio de referencias bibliográficas acerca da literatura. Ao final se irá conclui que a intervenção do psicopedagogo é de extrema importância para que o tratamento traga resultados positivos, por meio de oficinas psicopedagogicas, da psicomotricidade, das brincadeiras, e jogos em gerais, ou até mesmo atividades lúdicas pode proporcionar uma alteração muito favorável na vida dessa criança.

Palavras- chave: Aprendizagem. Psicopedagogia. Hiperatividade. Crianças. Jogos.

\section{INTRODUÇÃO}

Os primeiros Centros Psicopedagógicos foram fundados na Europa, em 1946, por J Boutonier e George Mauco, com direção médica e pedagógica." Estes Centros uniam conhecimentos da área de Psicologia, Psicanálise e Pedagogia, onde tentavam readaptar crianças com comportamentos socialmente inadequados na escola ou no lar e atender crianças com dificuldades de aprendizagem apesar de serem inteligentes. (MERY apud BOSSA, 2000, p. 39)

Esperava-se por meio desta união, Psicologia-Psicanálise-Pedagogia, conhecer a criança e o seu meio, para que fosse possível compreender o caso para determinar uma ação reeducadora. Diferenciar os que não aprendiam, apesar de serem inteligentes, daqueles que apresentavam alguma deficiência mental, física ou sensorial era uma das preocupações da época.

Observamos que a psicopedagogia teve uma trajetória significativa tendo inicialmente um caráter médico-pedagógico dos quais faziam parte da equipe do Centro Psicopedagógico: médicos, psicólogos, psicanalistas e pedagogos.Esta corrente européia influenciou significativamente a Argentina. (FERNANDEZ apud BOSSA, 2000, p. 41).

Com isso a Psicopedagogia surgiu na Argentina há mais de 30 anos e foi em Buenos Aires, sua capital, a primeira cidade a oferecer o curso de Psicopedagogia. A psicopedagogia chegou ao 
Brasil, na década de 70, cujas dificuldades de aprendizagem nesta época eram associadas a uma disfunção neurológica denominada de disfunção cerebral mínima.

Inicialmente, os problemas de aprendizagem foram estudados e tratados por médicos na Europa no século XIX e no Brasil percebemos, ainda hoje, que na maioria das vezes a primeira atitude dos familiares é levar seus filhos a uma consulta médica.

Visca apud Bossa (2000, p. 21) nos diz:

A Psicopedagogia foi inicialmente uma ação subsidiada da Medicina e da Psicologia, perfilando-se posteriormente como um conhecimento independente e complementar, possuída de um objeto de estudo, denominado de processo de aprendizagem, e de recursos diagnósticos, corretores e preventivos próprios.

A pscicopedagogia institucional-escolar, podemos considerar que, procura refletir sobre a aprendizagem do aluno, com a extrema relação com a informação e os conceitos em diferentes áreas do conhecimento, buscando os diagnósticos e ampliação da prática em sala de aula, junto com os professores, e pedagogos.

Com apoio esses profissionais são agentes que favorecem sentido a instituição, a proposta pedagógica acaba por ser institucional, esse trabalho é um novo espaço, onde se aprofundam as questões sobre as dificuldades de aprender e com isso, vai construindo para a instalação da intervenção preventiva:

Os profissionais da pscicopedagogia, passam a sentir e pensar e agir, novas ações frente o aprendizado dos próprios conceitos, na escola. Nesse contexto a construção onde estejam presentes a integração e a abertura para novas transdisciplinaridade.

O educador passa, nesse processo ideológico, a rever o seu próprio processo de aprender. O profissional de psicopedagogia contribui intelectualmente mas primeiramente com vivencias e práticas por meio de oficinas, por exemplo.

Uma disciplina que se detém em estudar e penetrar nas entranhas institucionais (relações de poder, ideologia etc) Uma política de intervenção psicosociopedagógica em instituições, organizações, e grupos.

Um movimento destinado a planejar, executar desenvolver e avaliar programas de intervenção objetivando transformar a realidade, pois dificilmente sob determinados pontos de vistas teóricos, é impossível, nessa estrutura atual, mudar a realidade de modo total. Isso se daria por meio de revolução armada. 


\section{OS PROCESSOS DA PSICOPEDAGOGIA.}

A psicopedagogia é um campo de atuação, que podemos identificar como a principio a junção da pedagogia com a psicologia, com o respectivo objetivo, o desenvolvimento de estratégias para ser trabalhada com crianças com dificuldades de aprendizagem, seja ela, na parte escolar, social e comportamental.

Uma das principais características dessa área é o acompanhamento, também de crianças que sofrem com o transtorno de déficit de atenção e hiperatividade, que mesmo a criança fazendo o tratamento com o médico e com os outros profissionais, não consegue suprir as suas limitações que estão extremamente ligada a área escolar.

O profissional da psicopedagogia, deve tomar a frente para tentar suprir as lacunas que ficaram existentes com a criança que sofreu com o transtorno.

Um dos principais problemas que é encontrado na sala de aula, com as crianças que apresentam TDAH (Transtorno de Déficit de Atenção e Hiperatividade), é o não fazer das lições, principalmente as de casa, pois elas não consegue se concertar para pode resolver os exercícios, com isso acaba deixando ela atrasada em relação aos outros alunos na sala, prejudicando o seu processo cognitivo, dentre outras as dificuldades mais comuns encontradas em crianças com TDAH é dificuldades em organização e orientação espacial, déficit viso motor, leitura deficiente, com uma acentuada dificuldade na interpretação de texto embora pode ter um bom vocabulário.

Alicia Fernándes (2001, p.29) afirma que:

Entre ensinante e o aprendente abre-se um campo de diferenças onde se situa o prazer de aprender. O ensinante entrega algo, mas para poder apropria-se daquilo o aprendente necessita inventa-lo de novo. È uma experiência de alegria, que facilita ou perturba, conforme se posiciona o ensinante. Ensinantes são os pais, os irmãos, os tios, os avós e demais integrantes da família, como também os professores e os companheiros na escola.

Ao final podemos dizer geralmente crianças que apresentam alterações no comportamento tem algum tipo de dificuldade de aprendizagem e ate interferindo no meio social, portanto há uma grande importância para que haja o tratamento psicopedagogico com crianças com TDAH.

\section{ALGUNS FUNDAMENTOS QUE A PSICOPEDAGOGIA PODE DAR A UMA CRIANÇA COM TDAH, NO AMBIENTE ESCOLAR.}

A psicopedagogia em si, tem varias áreas em que se pode atuar, a clinica que juntamente com uma equipe de profissionais trabalham em consultórios atendendo crianças com vários níveis 
com dificuldades de aprendizagem, e a área institucional, que pode ser tanto na área do ambiente escolar como na área de empresa, na escola atua juntamente com a equipe pedagógica como diretores, coordenadores, e professores, e nas empresas como profissional de treinamentos para o desenvolvimento do trabalhador.

Portanto dentro da escola as vezes falta profissionais altamente qualificados para que se possa trabalhar de forma correta com esses alunos intervindo no seu processo de aprendizagem, é claro que o professor como o responsável da sala, sozinho e precisando dar conta dos outros alunos na sala, a pressão vindo da diretoria sobre o conteúdo a passar para que se cumpre o objetivo especifico ao final do ano, a professora não tem como dar um ensino diferenciado a essa criança, que muitas vezes mesmo diante do seu tratamento sofre por esses e outros motivos encontrados na escola.

Mais do que importante é necessário que haja um psicopedagoga na escola para que se possa trabalhar com essas crianças, ao modo em que elas acabem se desenvolvendo e criando um certo vinculo diante dessa pessoa, para que consiga haver um processo de aprendizado, não fora da escola, mas que passa a atender esse aluno de acordo com a sua necessidade, que nos dias de hoje fica difícil tratar.

Um dos objetivos da psicopedagoga na escola é justamente forçar não só nos alunos com dificuldades de aprendizagem, como a dislexia ou discalculia, não sim também sobre as crianças que sofre com esse transtorno. Uma das maneiras que se pose utilizar é a utilização de jogos e brincadeiras para que haja um processo continuo.

Lembrando que a maioria dessas crianças que possuem o transtorno são crianças, portanto o uso de recursos como de jogos livres e de regras servem de maior resultado positivo, para o tratamento. Como já foi dito no segundo capitulo, a psicomotricidade pode servir como um recurso auto didático para esse processo.

Segundo LEVIN (2003, p.66) "[...] A Psicomotricidade nos enriquece com a idéia do fazer e do conhecer com o corpo. Mostrar ou não mostrar a ação é a psicopedagogia que nos direciona para o mostrar ou não mostrar o conhecimento".

Podemos destacar, também algumas terapias (psico) motoras, que buscam uma melhora da criança na escola e mesmo em casa, através de 'receitas' que buscam moldar seu comportamento através de exercícios, muitas vezes condicionadores. 
Traça-se um perfil psicomotor e se espera que a criança esteja dentro de uma média, do 'normal'. Se isso não acontece, inicia-se uma maratona de terapias 'psi', bem como há uma orientação à escola para que haja uma adequação dessa criança no meio escolar.

A psicomotricidade pode ser um instrumento não para ser trabalhado para o desenvolvimento do corpo em si, mas para o pensamento cognitivo também. Como já disse anteriormente que a freqüência desse distúrbio é maior em meninos do que em meninas, portanto é possível se utilizar toda essa energia existentes nos meninos, há favor do seu processo de aprendizagem.

Pode-se reparar que geralmente as crianças hiperativas se desenvolve melhor durante a aula de educação física, faz os exercícios de forma correta, respeita os professores, as vezes, tão até uma certa atenção aos amiguinhos que não estão conseguindo fazer a atividade, então por que já aproveitando toda essa energia, para se trabalhar de uma forma diferenciada com esses alunos.

Através da educação física, a criança desenvolve suas aptidões perspectivas como meio de ajustamento do comportamento psicomotor. Para que a criança desenvolva o controle mental de sua expressão motora, devera realizar atividades considerando seus níveis de maturação da biologia.

Com a sua didática é possível recrear, e ao mesmo tempo proporcionar a aprendizagem das crianças em varias atividades esportivas que ajudam na conversação da saúde física, mental e no equilíbrio socioafetivo.

A educação não pode ser totalmente dissociada ao esporte, já que um dos seus objetivos é em consistir em promover a socialização e a interação entre os seus alunos, proporcionando o reconhecimento do esporte.

É um fenômeno cultural que consiste em ações psicomotoras exercidas sobre o ser humano de maneira a favorecer determinados comportamentos permitindo assim, as transformações e as condições sociais.

Para Kishimoto (2007, p. 134)

O brinquedo, o jogo, o aspecto lúdico e prazeroso que existem nos processos de ensinar e aprender não se encaixar nas concepções tradicionais de educação que priorizam a aquisição de conhecimentos, a disciplina e a ordem como valores primordiais a serem cultivados nas escola. Esta dificuldade em olhar de modo inovador aspectos fundamentais e específicos da escola contribuir para limitar as ações que realmente colaborem para a afetivação de mudanças significativas nas práticas pedagógicas utilizadas hoje com crianças 
É claro que tudo isso fica difícil de se trabalhar em sala de aula, pois na escola pode ser aplicado como proposta de trabalho, exercida por uma psicopedagoga institucional, que através de jogos e brincadeiras, e com isso fazendo a utilização da aula de educação física, como recurso didático para o processo de aprendizagem para as crianças com TDAH.

A concepção que esboçamos apresenta o material pedagógico, como um objeto construído, durante o processo (ensino aprendizagem), que se funda em três elementos articulados básicos: o objeto pedagógico, a matéria-prima pedagógica e o substrato pedagógico. Com isso queremos dizer que o material pedagógico tem uma concretude ou essência, uma multiplicidade de imagens desta concretude e um símbolo representativo da mesma (MRECH, 1989, p. 50).

Um dos aspectos que também pode fazer diferença na aprendizagem da criança hiperativa, é através de oficinas criativas, que consegue envolver o aluno completamente na ação, por que tudo o que é novo e criativo chama a atenção da criança, também pode trabalhar com a concentração, a coordenação motora, atenção e o mais importante para esses tipos de alunos a criatividade onde é bem sutil na vida delas.

A flexibilidade e maleabilidade da argila adaptam-na ás necessidades mais variadas. Consideramos suas qualidades: ela é maravilhosa por que é mole, macia, sensual e faz sujeira, sendo atraente para qualquer idade. Promove a manifestação ativa de um dos processos internos mais primitivos. Proporciona a oportunidade de fluidez entre material e manipulador como nenhum outro. (ALLESANDRINI, 1996, p.93)

Essa é uma ótima alternativa onde a psicopedagogia se envolve, com o objetivo de criar e inovar ações, trabalhando com as crianças. As crianças com TDAH, tem uma enorme dificuldade em se concentrar nas coisas que estão acontecendo ao seu redor, com a oficina da argila, ela poderá relaxar e colocar sua criatividade em prática, afinal eles são mais criativos do que qualquer outra criança. Para Oaklander (1980, p. 85)

A argila mobiliza a tomada de decisão, trabalha a própria escolha do que se vai fazer e de que maneira. A cada movimento, é preciso fazer inferências na busca daquilo que foi uma escolha, exatamente para transformar em objeto o que se criou e imaginou no nível da representação mental. "Aqueles que estão inseguros e temerosos podem ser uma sensação de controle e domínio através da argila. Ela constitui um meio que pode ser desmanchado, e que não tem regras especificas definidas para os seus usos. É bastante difícil, cometer erros ao trabalhar com argila. Crianças que precisam fortalecer a sua auto-estima experimentam um senso incomparável de si próprias através do seu uso 


\section{CONCLUSÃO}

Ao final desse estudo, podemos perceber, que a área onde a psicopedagogia pode atuar, é muito ampla, partindo muito além do que imaginamos. Começando pelo contexto constituído do que é definitivamente TDAH (transtorno de déficit de atenção), as suas causas, e como a criança como sofre com esse problema.

Percebemos com esse trabalho, a importância da relação da psicopedagogia com a criança hiperativa, quais são os benefícios que ela pode trazer, em relação as lacunas que ficam abertas, mesmo com o tratamento. Em uma análise mais profunda sobre esse assunto podemos indicar formas de trabalhos para que sejam utilizados no processo de aprendizagem, favorecendo o aspecto cognitivo, social comportamental, e de identidade. O foque do trabalho foi justamente, saber que métodos a psicopedagogia pode utilizar dentro da escola, para colaborar com a aprendizagem da criança com TDAH.

O estudo revelou, que algumas ações dos jogos e brincadeiras podem ser subordinadas dos objetos, e que podem servir como contribuição para o desenvolvimento da criança. Sendo assim, utilizando atividades que favoreçam o envolvimento da criança com atividades que envolve a concepção em relação a função pedagógica e psicopedagogica.

Promover uma maior interação entre o aluno, professor, professor e pais, fazendo que a família tenha uma maior aproximação da vida escolar de seus filhos, participando de tudo que esta no cotidiano da sala de aula. Mostrar a importância que a família tem na vida da criança com TDAH, o que os pais devem saber e fazer, diante da dificuldade da criança.

Porém, foi atribuído a atuação da psicomotricidade como um elemento fundamental, para o acompanhamento do trabalho psicopedagogico, utilizado para se trabalhar de forma diferenciada com cada criança, utilizando a sua capacidade física e motora, e aproveitando o conhecimento prévio de cada um, de acordo com o seu meio social em que esta inserido.

O recurso da oficina criativa com argila, também pode ser utilizado como método para se trabalhar com crianças hiperativas, trabalhando o aspecto cognitivo e criativo de cada aluno.

Portanto os jogos, as brincadeiras, a psicomotricidade e a oficina pedagogia são elementos fundamentais, para ser trabalhados com crianças hiperativas, a criança que sofre com o transtorno é prejudicada em seu comportamento e no seu cognitivo, portanto a psicomotricidade trabalha mais a parte da coordenação como um todo, ou seja, a comportamento, já a oficina criativa, enfoca mais no aspecto intelectual e criativo, da criança, para que ela se estabeleça uma meta, em sua vida escolar. 
Enfim, os dois conceitos são de extrema importância para a ação do trabalho psicopedagogico, com as crianças que sofrem de TDAH, fazendo que ao final se tenha uma melhora em relação as lacunas que não foram fechadas durante o tratamento, mas que com muita dedicação vão sendo superadas durante o processo.

\section{REFERÊNCIAS}

ALLESSANDRINI, C, D. Oficina criativa e psicopedagogia, São Paulo, Casa do psicólogo, 1996.

BOSSA, N, A. A psicopedagogia no Brasil: contribuições a partir da prática, Porto Alegre, Artes médicas, 2000.

FERNÁNDEZ, A $\mathbf{O}$ saber em jogo. A psicopedagogia propiciando autorias de pensamento. Porto Alegre, Artmed, 2001.

KISHIMOTO, T, M. Jogo, brinquedo, brincadeira e a educação. São Paulo: Cortez, 2007.

LEVIN, E. A clínica psicomotora: o corpo na linguagem. 5a ed. Trad. Julieta Jerusalinsky. Petrópolis: Vozes, 2003.

MRECH, Leny M. O espelho partido e a questão da deficiência mental moderada e severa em seu vínculo com as estruturas de alienação no saber. São Paulo, Ipusp, 1989.

OAKLANDER, V. Descobrindo crianças. A abordagem gestáltica com crianças e adolescentes, São Paulo, Summus, 1980. 